\title{
Lifestyle and Sociodemographic and Economic Characteristics of Patients with Lung Cancer in Morocco
}

\author{
Imane Harkati $\left(\mathbb{D},{ }^{1}\right.$ Mohamed Kamal Hilali, ${ }^{1}$ Nezha Oumghar, ${ }^{2}$ Mouna Khouchani, ${ }^{2}$ \\ and Mohamed Loukid ${ }^{1}$ \\ ${ }^{1}$ Laboratory of Human Ecology, Semlalia Faculty of Sciences, Cadi Ayyad University, Marrakech, Morocco \\ ${ }^{2}$ Oncology Department, Center of Oncology and Hematology, Mohammed VI Hospital Center, Marrakech, Morocco \\ Correspondence should be addressed to Imane Harkati; imaneharkati@gmail.com
}

Received 19 August 2019; Revised 25 November 2019; Accepted 13 December 2019; Published 10 January 2020

Academic Editor: Hisao Imai

Copyright (C) 2020 Imane Harkati et al. This is an open access article distributed under the Creative Commons Attribution License, which permits unrestricted use, distribution, and reproduction in any medium, provided the original work is properly cited.

\begin{abstract}
Background. Lifestyle maintenance is a crucial condition before and after lung cancer disease. According to the previous research in the scientific databases, the effect of the interaction between socioeconomic and demographic factors on the lifestyle of lung cancer patients in Southern Morocco regions remains unexamined. Accordingly, this study was designed to examine the relationship between socioeconomic factors, demographic factors, and the lifestyle of lung cancer patients. Methods. A total of 133 patients with lung cancer were divided into 103 men and 30 women with a sex ratio of 3.43 and ages varying between 28 and 82 years, and they served as informants for the study and filled in a questionnaire to provide information on their sociodemographic background, various economic characteristics, and their lifestyle. These patients have also been submitted to an anthropometric examination following the standardized procedure recommended by the World Health Organization. The survey was conducted from July 2013 to March 2015 at the Oncology and Radiotherapy Department, at Mohammed VI Hospital Center in Marrakech, Morocco. Results. The preliminary results showed that the average age of patients was $59 \pm 9$ years. A proportion of $81 \%$ lived in the Marrakech-Safi region and 19\% lived in four other southern regions. Among the patients, $6 \%$ were smokers, while $14 \%$ were nonsmokers and $80 \%$ were ex smokers. Following the discovery of the disease, $26 \%$ revealed that they had sleep disorders and $98 \%$ were reported to have a lack of appetite. Obesity, normal weight, and underweight were also taken as criteria to categorize the patients; thus, obese informants represented $23 \%$ of the total number, those having normal weight reached $67 \%$ and the patients having underweight represented $10 \%$. Conclusion. Sociodemographic variables and various economic characteristics were shown to have a negative impact on the lifestyle of lung cancer patients.
\end{abstract}

\section{Introduction}

Most cancers in the world go undetected until the disease reaches an advanced stage, at which point the severe symptoms require diagnosis. Probably, the patients' low lifestyle due to their poor economic level cannot allow them to an easy attain for a priori diagnosis. Therefore, it is important to lead a higher lifestyle to have an easy access to clinical treatment and to attain significant survival rates $[1,2]$.

One man among five and one woman among six worldwide develop cancer during their lifetime. Moreover, one man among eight and one woman among eleven die of the disease [3]. The lifestyle of lung cancer patients is affected not only by their symptoms but also by their daily negative behavior $[4,5]$. Normally, their daily life behavior resulting out of their low level of lifestyle leads to the increase of lung cancer risk $[6,7]$. Being physically active might decrease the risk of lung cancer. On the contrary, consuming red meat, high body mass index, low fruit and vegetable intake, lack of exercise [8], and alcoholic drinks might increase the risk of lung cancer $[9,10]$.

In the United States, women die of more smoking-induced lung cancer than breast cancer. In some Nordic countries, lung cancer kills more women than men [6]. In fact, it is the first type of cancer among men in most Northern African Countries, notably Morocco with 31.9 per 100,000 [11]. 
In Morocco, lung cancer represents one of the major problems of public health. Indeed, the World Health Organization estimates that the annual number of new cases among men is 3,497. Besides, 12,500 men and 10,400 women die each year in the country [8]. The figures published on the incidence and mortality of cancer in Morocco are only estimations. In fact, there are only a few regional cancer records. For this reason, we conducted this epidemiological study to enrich the scientific and statistical knowledge on lung cancer in the southern region of the country.

The major problems of providing oncological care for patients with lung cancer in Morocco are the medical demography, the unequal distribution of professionals, and the health resources in the health regions of the country.

Generally, the great difficulty in accessing oncology care is due to the fact that patients are most often diagnosed at very advanced stages of the disease. At the national level, the diagnosis of lung cancer made at stage I or II attains only $4 \%$ of cases, while $96 \%$ of cases are diagnosed at stages III and IV [12]. Since the creation of Lalla Salma Foundation on November 22, 2005, the fight against cancer in Morocco has become a public health priority. To this end, the Foundation and the Ministry of Health have developed the National Plan for Prevention and Control of Cancer 2010-2019 [13].

Morocco's economic situation is developing at a rapid pace, and the standard of living is improving. This scenario has also resulted in sedentary lifestyles, unhealthy eating habits, smoking, alcohol consumption, urbanization, and the aging of the population. In this respect, our study aims at improving the management system and care for lung cancer patients and also developing all health professionals' importance of lifestyle outcomes in these patients.

The study will focus on monitoring changes in patients' weight related to cancer, dietary recommendations, exercise capacity, mental state, sleep habits, etc. In a context of etiological and analytical epidemiology, this study aims to examine the relationship between certain sociodemographic factors and the lung cancer patients' lifestyle in Southern Morocco.

\section{Materials and Methods}

2.1. Study Design. This study has a descriptive nature, applying a retrospective analysis of the data using anthropological and epidemiological approaches. A data collection about lung cancer disease was carried out for two years, starting from July 2013 until March 2015, applying a wellstructured questionnaire on a sample of 133 patients (103 men and 30 women) at the center of oncology and hematology of the University Hospital Center of Marrakech. The study was conducted after approval of the protocol by "Mohamed VI Hospital Ethics Committee"; informants' consent was obtained in the study before data collection started.

The patients came from five different southern regions: Marrakech-Safi, Béni Mellal-Khenifra, Souss-Massa, DrâaTafilalet, and Laâyoune-Sakia. These regions represent a number of $12,034,605$ citizens, which is equivalent to $34.51 \%$ of the total Moroccan population. The survey was conducted by selecting a representative sample of the Moroccan
Southern population through a purposive and quota sampling. The patients surveyed visit the center either for a first consultation, for a more precise follow-up of the evolution of the disease, or for serious health complications. The selection of patients was done in a structured way, respecting the inclusion criteria and the exclusion criteria. Accordingly, we have chosen patients who suffer from lung cancer, regardless of the stage and the cell type of the disease, while children and pregnant women together with patients having lung metastasis of another type of cancer were excluded.

Our sample is obviously representative because it is formed according to the purposive and the quota method through which we observe the criteria of sex, age, socioprofessional categories, region, etc. This sample that we studied represents the same characteristics as the southern population of Morocco, where we used a comprehensive selection of all cases of lung cancer patients without prejudice. Besides, the hospital where we carried out the study is the largest of the 4 hospitals in Marrakech and the only public hospital for the diagnosis and treatment of cancer of all patients from the southern regions.

2.2. Material Support. The dependent variable in our study is lung cancer, defined as C34.0-C34.9, which represent malignant neoplasm of bronchus and lung. The subsites of C34.0 through C34.9 are considered part of a single primary site. They represent lesions in the main bronchus excluding Carina (C34.0), in upper, middle, and lower lobes (C34.1, C34.2, and C34.3) and in overlapping lesion (C34.8) of lung, which can also be unspecified (C34.9).

We conducted a survey of patients based on a structured questionnaire and on their recorded medical files which included the history of their disease and the measured diagnosis tests. This questionnaire includes a division of independent variables, which are defined on the basis of ICD10 codes: sociodemographic data, economic variables, and lifestyle.

2.2.1. Social Criteria. Educational level (illiterate, primary, secondary, or higher): this is coded Z55.0, which represents illiteracy and low-level literacy in the section of problems related to education and literacy (Z55); marital status (married, divorced, widowed, or single): it is coded Z63.4, which represents disappearance and death of family members, and Z63.5 represents disruption of family by separation and divorce in the section of problems in the relationship with spouse or partner (Z63.0).

2.2.2. Demographic Criteria. Age and sex: ages between 28 and 82 years for both women and men; place of residence: from five south different regions; birth rank: eldest, middle child, or youngest.

2.2.3. Economic Criteria. Professional status (active or inactive): it is coded Z56.0, which represents unemployment, unspecified in the section of problems related to employment and unemployment (Z56); habitat type (apartment, 
traditional house, villa, and hut): it is coded Z59.1 and represents inadequate housing in the section of problems related to housing and economic circumstances (Z59); personal and additional incomes: it is coded Z59.6, which represents low income in the section of problems related to housing and economic circumstances (Z59).

2.2.4. Lifestyle Criteria. Body mass index before and after the disease: obesity, normal, or underweight; social interaction (isolated or sociable): it represents living alone and social exclusion and rejection on the basis of illness in the section of problems related to social environment; sports practice: it represents limitation of activities due to disability in the section of problems related to life management difficulty; appetite status: it represents inappropriate diet and eating habits in the section of problems related to lifestyle; sleep: disorder and insomnia; sedentary behavior: TV, Internet, and games; behavioral habits (alcohol consumption, smoking status, and nutrition): it represents tobacco use and alcohol use in the section of problems related to lifestyle and also passive exposure to tobacco smoke presented in the section of problems related to physical environment.

2.3. Statistical Analyses. The collected data were coded, captured, and validated. The analysis consisted in a description of the sample according to the sociodemographic characteristics, residence and health conditions of the patients, and their way of life before and after the illness. The description procedure allowed us to describe the distribution of continuous variables and to verify measures of central tendency and dispersion. The correlation test facilitated the determination of the absence or the presence of a significant linear relationship between the continuous variables.

Factors that may influence lung cancer have been the subject of univariate and bivariate analyses to test the possible associations, using the chi-square test to compare qualitative variables with a risk of error granted at $5 \%$ and a significance set at $p<0.05$. The chi-square test was used to test the null hypothesis of the absence of a relationship between two categorical variables and to verify the hypothesis of the independence of these variables. It is based on the comparison of the numbers observed with the theoretical numbers and the calculation of the difference between them. When the difference is very small and does not exceed a theoretical value of chi-square for the corresponding number of degrees of freedom, the two variables are independent of each other. The statistical analyses were performed using the software (IBM SPSS version 20) Statistical Package for the Social Sciences (SPSS Inc., Chicago, Illinois, USA) and expressed as mean \pm SD or percentage with significant value.

\section{Results}

3.1. Descriptive Characteristics of the Study Population $(N=133)$. The mean age of patients was $59 \pm 9$ years. Table 1 shows that $23 \%$ of women and $77 \%$ of men in the sample were counted, $35 \%$ were professionally active,
TABle 1: Distribution of sociodemographic and economic characteristics of patients with lung cancer in the southern regions of Morocco.

\begin{tabular}{lc}
\hline Characteristics & $\%$ \\
\hline Age (years) & 2 \\
$<40$ & 55 \\
Between 40 and 60 & 40 \\
Between 60 and 80 & 3 \\
$>80$ & \\
Sex & 23 \\
Women & 77 \\
Men & \\
Professional status & 35 \\
Active & 65 \\
Inactive & \\
Marital status & 83 \\
Married or remarried & 7 \\
Divorced & 5 \\
Widowed & 5 \\
Single & \\
Place of residence & 6 \\
Souss-Massa & 2 \\
Laâyoune-Sakia & 4 \\
Drâa-Tafilalet & 81 \\
Marrakech-Safi & 7 \\
Béni Mellal-Khenifra & \\
Level of study & 43 \\
Illiterate & 25 \\
Primary & 26 \\
Secondary & \\
Higher & \\
\hline
\end{tabular}

$83.5 \%$ were married, and only $6 \%$ had a higher level of education as opposed to $43 \%$ who were illiterate. The distribution of the patients according to their place of residence was as follows: Marrakech-Safi (81\%), Béni Mellal-Khenifra (7\%), Souss-Massa (6\%), Drâa-Tafilalet (4\%), and Laâyoune-Sakia (2\%).

The personal and the additional incomes of the studied population were, respectively, $51 \%$ and $64 \%$. Table 2 shows that $20 \%$ of cases had family antecedents of cancer while $4 \%$ had personal antecedents of cancer.

A percentage of $32 \%$ among patients had cardiovascular diseases, and only $5 \%$ of them had rheumatology diseases. Besides, the most remarkable symptoms before the disease diagnosis were coughing, chest pain, dizziness, vomiting, spitting of blood, fever, asthenia, and edema.

3.2. Lifestyle: Factors Associated with Lung Cancer. The presence of other diseases and the need for the discovery of the disease were, respectively, strongly related to body mass index (BMI) before the disease with a $p=0.01 / x^{2}=33.15$ and a $p=0.006 / x^{2}=32.13$.

A number of variables were not associated with the personal history of cancer: social behavior, sedentary behavior, and lifestyle $\left(p=0.71 / x^{2}=0.13 ; p=0.83 / x^{2}=0.04\right.$; $p=0.68 x^{2}=0.16$, respectively). As we found out in our research, $97 \%$ prefer an isolated lifestyle, watching television, and had difficulty in their lifestyle. 
TABLE 2: Clinical characteristics and personal and family history of lung cancer disease in the studied population.

\begin{tabular}{lc}
\hline Characteristics & $\%$ \\
\hline Personal antecedent of cancer & \\
Yes & 4 \\
No & 96 \\
Family antecedent of cancer & 20 \\
Yes & 80 \\
No & \\
Presence of other diseases & 29 \\
Yes & 71 \\
No & \\
Types of other diseases & 25 \\
Pneumatological & 32 \\
Cardiovascular & 10 \\
Digestive & 5 \\
Rheumatology & 28 \\
Endocrine & \\
\hline
\end{tabular}

The percentage of smokers was particularly high in men (92\%) compared with that in women (7\%), with $p=0.00$ and $x^{2}=89.2$. Among daily smokers, $2 \%$ of women smoke an average of one pack per day compared to $98 \%$ of men who smoke a pack or two a day.

Current smokers (5.3\%) plan to quit smoking one day, while nonsmokers (27.1\%) express their fear to be subject to lung cancer, most often justifying this feeling by referring to passive smoking; some patients think that breathing the air of cities is as bad for health as smoking cigarettes while others recognize that some people can smoke all their lives without ever getting sick.

We obtained $69 \%$ of patients who quit smoking for 10 years before diagnosis, and $28 \%$ of them were illiterates compared to $8.8 \%$ with a higher level of education. The average age of patients at the initiation of regular smoking is roughly the same for both sexes: 20.3 years for men and 20 years for women. We also found that $45 \%$ of patients consume one pack a day and 55\% consume it at work.

Habitat type was also related to monthly income with a statistically significant association $\left(p=0.01 / x^{2}=10.53\right)$, and this rate was the lowest (12\%) among patients who have no income and who live in huts, while $88 \%$ of patients with an income live in a house.

Table 3 shows a strong, statistically significant relationship between the presence of other diseases and the need for the discovery of lung cancer $\left(p=0.006 / x^{2}=16.15\right)$, whereas $20 \%$ patients had cough, fever, and digestive pain, $23 \%$ had mild tumor and limb pain, and $10 \%$ had sputum with blood.

A statistically significant relationship between the type of profession and consumption of canned goods was found among $44 \%$ of patients (18.5\% farmers, $13.6 \%$ workers, and $12.5 \%$ craftsmen). Also, we found a very strong statistically significant relationship between the type of profession and consumption of salted and dried meat (quadid). This is found among $44 \%$ of patients, including $16.5 \%$ farmers, $12.6 \%$ workers, and $15.5 \%$ craftsmen. In addition, a very strong statistical significance was established between the type of profession and the level of education among $65 \%$ of
TABLE 3: The associations between clinical and socioeconomic factors, with the type of profession and with the presence of other diseases in patients with lung cancer.

\begin{tabular}{|c|c|c|c|}
\hline \multirow{2}{*}{ Variables in association } & \multicolumn{3}{|c|}{ Controlled variable } \\
\hline & $\chi^{2}$ & $p$ & $\%$ of patients \\
\hline \multicolumn{4}{|l|}{ The type of profession } \\
\hline Consumption of canned goods & 18.79 & 0.04 & 44 \\
\hline $\begin{array}{l}\text { Consumption of salted and dried } \\
\text { meat (Quadid) }\end{array}$ & 21.22 & 0.02 & 44 \\
\hline Level of education & 94.46 & 0.00 & 65 \\
\hline \multicolumn{4}{|l|}{ The presence of other diseases } \\
\hline Fast food and Smen consumption & 17.2 & 0.04 & 69 \\
\hline Birth rank of the patient & 31.8 & 0.02 & 66 seniors \\
\hline $\begin{array}{l}\text { Need for the discovery of the } \\
\text { disease }\end{array}$ & 16.15 & 0.006 & 53 \\
\hline
\end{tabular}

Quadid: dried meat with salt; Smen: butter conserved with salt.

patients: $22.8 \%$ farmers, $33.3 \%$ unemployed, and $8.9 \%$ craftsmen were illiterate.

Among food factors, canned food consumption, oil reuse, and home storage of quadid and khlii are significantly related to lung cancer. While consuming little or no fruit, brine and soft drinks are at greater risk of contracting the disease but not significantly.

In terms of environmental factors, professional toxic exposure increases the risk of lung cancer. Besides, a toxic smoking habit is significantly related to the disease. Also, we found that overweight, sedentary lifestyle, and lack of exercise are independent risk factors, but in the presence of additive effects, they will also be involved in the occurrence of lung cancer.

Finally, there was no statistically significant relationship between the educational level and the consumption of medicinal plants $\left(p=0.06 / x^{2}=7.48\right)$. Thus, there was no statistically significant link between the place of residence and the consumption of brines $\left(p=0.06 / x^{2}=9.13\right)$ in the studied population.

\subsection{Evolution of Lung Cancer Patients' Living Conditions.} Figure 1 shows that before the disease, $53 \%$ of the patients had overweight problems or obesity and $46 \%$ had normal weight while only $1 \%$ were suffering from underweight. However, after the illness, the frequency of overweight or obesity was only $23 \%$, while $67 \%$ of patients were with normal weight and $10 \%$ were below normal weight.

Table 4 shows several changes occurring at the level of the patient's living conditions. For example, $98 \%$ of them are suffering from insomnia, 93\% show a lack of appetite, and $94 \%$ are isolated.

\section{Discussion}

We studied the lifestyle of patients who were treated for lung cancer and the factors associated with it. This retrospective study was carried out on a representative sample of patients followed in two departments of the Center of Oncology and 


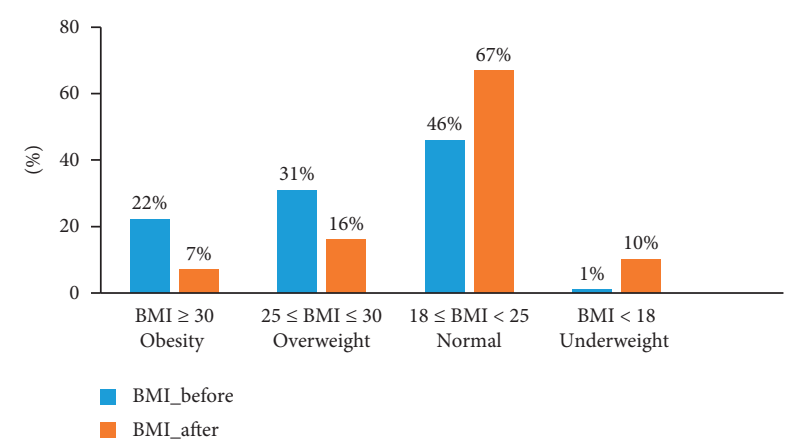

Figure 1: Body mass index (BMI) level before and after lung cancer.

TABLE 4: Changes in behavioral state and lifestyle of patients after lung cancer.

\begin{tabular}{lc}
\hline State & \% of patients \\
\hline Insomnia & 98 \\
Lack of appetite & 93 \\
Social interaction & 94 isolated \\
Absence of sport & 98 \\
Sensation of pain & 20 \\
Financial issues & 21 \\
Weight $<70$ & 71 \\
\hline
\end{tabular}

Hematology at Mohammed VI University Hospital Center in Marrakech.

As we have worked on a representative sample of 133 patients, we believe that our population can be considered representative of the lung cancer cases that have access to the health system in South Morocco. The absence of cancer records in the southern region during the time of the study did not allow us to know the real status of the different types of cancer.

To our knowledge, this is the first study on the lifestyle of lung cancer patients and the first initiative to assess the level of awareness of certain lung cancer protection parameters in southern Morocco. Lifestyle analysis in lung cancer is affected by some general sources of bias that have become particularly important because of the epidemiological and prognostic specificities of the disease. Indeed, lung cancer is currently classified as small cell lung cancer (SCLC), which is the most dangerous form, accounting for $10-15 \%$ of bronchopulmonary cancers, characterized by rapid growth and early metastasis. However, the second type is non-smallcell lung cancer (NSCLC), which includes squamous cell carcinoma and adenocarcinoma and represents nearly 85\% of cases. In addition, small-cell bronchial carcinoma most often occurs in central lung localization and primarily affects people with a history of smoking, while the epidemiology of adenocarcinoma is not as conditioned by smoking [14].

The results obtained showed that demographic and socioeconomic characteristics reflected poorly controlled living conditions that contribute to the increase of lung cancer. The key results of this study showed that men seem to be more affected than women with a sex ratio of 3.43. The distribution by age was between 28 and 82 years with an average age of $59 \pm 9$ years. We found a high frequency for the patients sampled between their forties and their eighties (95\%), while the affected population under 40 years was almost inexistent. They also had a low education level, often jobless or working primary and secondary sectors. As far as food factors are concerned, canned food consumption and home storage of quadid and khlii (dried meat cooked with boiling fats) are significantly related to the disease. From another perspective, consuming little or no fruit, brine, and soft drinks may increase the risk of contracting the disease, although it was not significantly proved. The analysis of food consumption showed that there was a significant relationship between the type of profession with the consumption of canned foods and the consumption of salted and dried meat. Regarding the smoking status, we have reached that the factors that led to smoking cessation are education and selfconfidence. Besides, we have noticed that the stopping rate seems easier among the most graduates, senior managers, and intermediate professions. On the other hand, we also point out that the low prevalence of smoking among women should not prevent the implementation of prevention actions among women who are considered a potential target of the tobacco industry.

Wintner et al. (2013) found that the average age of patients was 69 years, and $68 \%$ of them were men [15]. Contrarily, 59 years was the average age in our study. Also, we found that $97 \%$ of men and $100 \%$ of women were over the age of 40 .

According to Gridelli et al. , lung cancer is frequently diagnosed in elderly patients [16]. The result we reached in our study confirmed that $42 \%$ of patients were over the age of 60 . After giving up smoking for a period of time ranging from five to nine years, some patients can run just half the risk of lung cancer as compared to those who continue smoking [17]. We obtained $69 \%$ of patients who stopped smoking since 10 before diagnosis.

In the majority of Western countries, in particular, the United States and Western Europe, smoking is much more prevalent than in most North African countries such as Morocco, where the tobacco epidemiology has been established more recently [18]. In a multinational study evaluating smoking rates in the Middle East and North Africa, the lowest smoking rate was reported in Morocco (15.3\%) [19].

We found that $45 \%$ of patients consume one pack per day and $55 \%$ consume it at work. And the average age of smoking initiation in the regions of South Morocco was 18 years. A proportion of $50 \%$ of smokers had first cigarette consumption before the age of 18 . The average age at initiation of smoking in the United States is 15 years, with $87 \%$ of smokers having first smoked cigarettes before the age of 18 [20].

A proportion of $91 \%$ among 71,000 men were subject to lung cancer death. Also, the death of $77 \%$ out of 24,000 women was attributable to smoking [21]. The smoking status of nonsmoking women (21\%) indicates that passive inhalation of tobacco smoke causes an increase in the risk of lung cancer in women. There is evidence that about $90 \%$ of all lung cancers are related to active inhalation of tobacco smoke [11]. An additional 5\% may be associated with exposure to carcinogens at the workplace and radiation 
(radon) [22]. In the same context, we focused on four major sources leading to cancer covered by Doll and Peto (2015), namely, tobacco (the largest), food and nutrition (the most uncertain), profession (currently, the most controversial), and the most imminent infections [23].

Blot and Tarone [23] found that $20 \%$ of lung cancers may be diet-related [21]. While in our study more than $60 \%$ of patients were reported to consume food rich in salts (quadid (77\%): meat and salty fat; khlii (65\%): salty meat; smen (70\%): butter salty; preserves (61\%)), thereby these results agree with Blot's study.

In Morocco, the awareness of the risks of cancer associated with excessive alcohol consumption is necessary because of the increase in the prevalence of cancer and the consumption of alcohol in recent years. Although alcohol is a risk factor for many types of cancer [24], the frequency of alcohol consumption per month is more than 4 liters for $24 \%$ of patients. Beer is the most consumed alcoholic beverage with a percentage of 48 .

The personal antecedents of the presence of other diseases most related to lung cancer were cardiovascular, rheumatoid, endocrine, pneumatological, and digestive nature. This result can be explained by the high proportion of these patients whose lifestyle is low.

The subjects with a family antecedent of cancer were less consultant to traditional healers and were most consultant to medical institutions than those who did not have any cancer's family antecedent. This result can be related to the sensitization of patients with a family antecedent of cancer to the severity of the disease and the importance of care and proper medical follow-up.

A study carried out in 2015 found that a number of common clinical problems affect lifestyle and survival in cancer patients, including decreased appetite, frailty, fatigue and decreased activity, weakness, and nausea [25]. This result is consistent with our study, which showed that there is nearly a total absence of sports (98\%), lack of appetite (93\%), and lack of social interaction after illness (94\%). In fact, $98 \%$ of the population in our study had insomnia.

We found that $71 \%$ weighed less than $70 \mathrm{~kg}$ after the illness, which is consistent with the study of Aldige [21] who found that nearly $60 \%$ of lung cancer patients lost a lot of weight at the time when they are diagnosed, often due to late diagnosis, and $25 \%$ to $50 \%$ of these patients are considered malnourished [26].

These important lifestyle factors should be incorporated into the treatment plan at the time of diagnosis and followed throughout the stages of the disease. Other factors such as the stage of cancer or the overall patient health are often used as predictors of survival [21], but in this study, lifestyle at baseline was a better predictor of survival than those two more traditional criteria. About $70 \%$ of patients had discovered the disease in less than a year without considering their stage of evolution.

In the study of Najdi et al., the most closely related cancer site to sleep disorders is the pulmonary localization with a rate approaching $85 \%$ [27]. This can be explained by the result found in our study; about $98 \%$ have been found to suffer from insomnia.
In recent years, based on studies from Norway, South Korea, and different European cities, increased risk of chronic lung diseases was found to be more common in deprived communities and in people with low levels of education and with low socioeconomic status. This can partially be explained by differences in the prevalence of harmful health behaviors, including excessive smoking and poor nutrition [28].

The results of this work encourage us to think about the rapid introduction of measures to promote an active and global follow-up of patients with lung cancer. It should be noted that knowledge of the risk factors for cancer is a determining factor in the process of behavioral change [29].

The strengths of this study lie in its originality being able to highlight the importance of the results of the risk factors and lifestyles of lung cancer patients to improve the management system and care for these patients and develop the most appropriate practices for all health professionals. There are few regional cancer records in the country, and there is no record in the southern regions; hence, the epidemiological study that we conducted lead to prevention actions that are more effective and much less expensive than therapeutic efforts. Moreover, the novelty's pieces of evidence related to this study are manifested in determining the prevalence of lung cancer and its interaction with lifestyle factors for the first time among the Southern region's population that differs from the Northern region's population in their customs, rituals, and behaviors.

Our study, however, has a number of limitations: until 2013, Mohamed VI University Hospital Center represented the only public institution of care for cancer in the region of South Morocco. In addition, the private sector (represented in 2013 by a single private clinic specializing in cancers) is recruiting a very small proportion of cancer cases in South Morocco. Besides, the majority of patients seen at the hospital came from low- and middle-income socioeconomic levels. The smallest proportion of patients from the upper and upper socioeconomic classes seeks care in the few clinics and private hospitals in Marrakech.

Finally, this study shows the need for widespread and systematic public awareness of the lung cancer problem but also the extension of lifestyle surveillance, the expansion of the patient care network, and early detection of lung cancer in the southern region of Morocco.

\section{Conclusion}

The unstable patient living conditions should encourage all health care professionals of the oncology department to work together to take the necessary steps to resolve them.

In response to the purpose of our study, it seems that the use of tobacco and exposure to an environmental factor of risk as tobacco smoke can increase the risk of contracting lung cancer and even be correlated with the disease for people already weakened by food factor. In other words, it seems that food and environmental risk factors would be potentially responsible for the cause of the disease. We also found a regional variability, of exposure to the risk factors of lung cancer, which explains its gradient of incidence in the south of Morocco, in particular, those related to the lifestyle, 
to the consumption of food and to the professional environment.

The results show that there was a statistically significant difference in the lifestyle, in the physical and nutritional domains. Lifestyle was rated low in emotional status compared to other domains. This could be mainly noticed because of their physical appearance and their psychic suffering, which prevents them from participating in social gatherings and family functions.

The results of this work demonstrate the complexity of the networks of factors that can lead to carcinogenesis and provide also valuable information that could be used to put in place valuable lung cancer prevention strategies in South Morocco. From a global perspective, there is a clear need to closely examine the epidemiology of lifestyle and living conditions before and after lung cancer disease. Knowledge of the risk factors associated with lung cancer and the early prediction of these complications in patients may be useful in clinical practice, particularly, for implementing early preventive measures.

\section{Data Availability}

No data were used to support this study.

\section{Ethical Approval}

All procedures performed in this study involving human participants were in accordance with the ethical standards of the institutional and/or national research committee and with the 1964 Helsinki Declaration and its later amendments or comparable ethical standards.

\section{Consent}

Informed consent was obtained from all individual participants included in the study.

\section{Conflicts of Interest}

The authors declare that they have no conflicts of interest.

\section{Acknowledgments}

The authors thank all the staff of the Oncology and Hematology Center, especially the Oncology Department and the Radiotherapy Department of Mohamed VI Hospital Center for their collaboration and help in the collection of data and samples. The authors also thank all patients and their families for their participation in this study.

\section{References}

[1] J. S. Temel, J. A. Greer, A. Muzikansky et al., "Early palliative care for patients with metastatic non-small-cell lung cancer," New England Journal of Medicine, vol. 363, no. 8, pp. 733-742, 2010.

[2] X. S. Wang, Q. Shi, C. Lu et al., "Prognostic value of symptom burden for overall survival in patients receiving chemotherapy for advanced nonsmall cell lung cancer," Cancer:
Interdisciplinary International Journal of the American Cancer Society, vol. 116, no. 1, pp. 137-145, 2010.

[3] World Health Organization, Profils des Pays pour le Cancer (Maroc), World Health Organization, Geneva, Switzerland, 2014.

[4] S. Iyer, G. Taylor-Stokes, and A. Roughley, "Symptom burden and quality of life in advanced non-small cell lung cancer patients in France and Germany," Lung Cancer, vol. 81, no. 2, pp. 288-293, 2013.

[5] M. Delgado-Guay, S. Yennurajalingam, H. Parsons, J. L. Palmer, and E. Bruera, "Association between self-reported sleep disturbance and other symptoms in patients with advanced cancer," Journal of Pain and Symptom Management, vol. 41, no. 5, pp. 819-827, 2011.

[6] I. Henoch, A. Ploner, and C. Tishelman, "Increasing stringency in symptom cluster research: a methodological exploration of symptom clusters in patients with inoperable lung cancer," Oncology Nursing Forum, vol. 36, no. 6, 2009.

[7] I. Henoch and M. Lövgren, "The influence of symptom clusters and the most distressing concerns regarding quality of life among patients with inoperable lung cancer," European Journal of Oncology Nursing, vol. 18, no. 3, pp. 236-241, 2014.

[8] M. H. Forouzanfar, A. Afshin, L. T. Alexander et al., "Global, regional, and national comparative risk assessment of 79 behavioural, environmental and occupational, and metabolic risks or clusters of risks, 1990-2015: a systematic analysis for the global burden of disease study," The Lancet, vol. 388, pp. 1659-1724, 2016.

[9] M. K. Park, H. Y. Paik, and Y. Lee, "Intake trends of red meat, alcohol, and fruits and vegetables as cancer-related dietary factors from 1998 to 2009," Osong Public Health and Research Perspectives, vol. 7, no. 3, pp. 180-189, 2016.

[10] X. Xue, Q. Gao, J. H. Qiao, J. Zhang, C. P. Xu, and J. Liu, "Red and processed meat consumption and the risk of lung cancer," International Journal of Clinical and Experimental Medicine, vol. 7, no. 6, p. 1542, 2014.

[11] World Health Organization, The International Agency for Research on Cancer (IARC) Report, World Health Organization, Geneva, Switzerland, 2018.

[12] F. Soumia, A. Leila, R. Mohamed, H. Laila, and E. Mustapha, "Intérêt de la TEP-TDM dans le cancer broncho-pulmonaire primitif non à petite cellule," Pan African Medical Journal, vol. 28, no. 1, 2017.

[13] R. Bekkali, "Cancer control in Morocco: the contribution of Lalla Salma foundation," International Journal of Medicine and Surgery, vol. 4, pp. 55-59, 2017.

[14] HAS, Guide du parcours de soins. Tumeur maligne, affection maligne du tissu lymphatique ou hématopoïétique. Cancers bronchopulmonaires. July, 2013.

[15] L. M. Wintner, J. M. Giesinger, A. Zabernigg et al., "Quality of life during chemotherapy in lung cancer patients: results across different treatment lines," British Journal of Cancer, vol. 109, no. 9, pp. 2301-2308, 2013.

[16] C. Gridelli, E. Cortesi, and F. Roila, "Survival and quality of life: comparing end points in oncology," Annals of Oncology, vol. 12 , no. 3, p. S1, 2001.

[17] D. Schottenfeld and J. Fraumeni, Cancer Epidemiology and Prevention, Oxford University Press, Oxford, UK, 2006.

[18] M. Thun, R. Peto, J. Boreham, and A. D. Lopez, "Stages of the cigarette epidemic on entering its second century," Tobacco Control, vol. 21, no. 2, pp. 96-101, 2012. 
[19] A. Khattab, A. Javaid, G. Iraqi et al., "Smoking habits in the Middle East and North Africa: results of the BREATHE study," Respiratory Medicine, vol. 106, no. 2, pp. S16-S24, 2012.

[20] US Department of Health and Human Services, "The health consequences of smoking 50 years of progress: a report of the surgeon general. Atlanta, centers for disease Control and prevention. National center for chronic disease prevention and health promotion," Office on Smoking and Health, vol. 17, 2014.

[21] C. Aldige, Improving the Quality of Life for Lung Cancer Patients, Press Releases Lungcan ${ }^{\circledR}$ Capitol Hill, Washington, DC, USA, 2015.

[22] C. Svensson, G. Eklund, and G. R. Pershagen, "Indoor exposure to radon from the ground and bronchial cancer in women," International Archives of Occupational and Environmental Health, vol. 59, no. 2, pp. 123-131, 1987.

[23] W. J. Blot and R. E. Tarone, "Doll and Peto's quantitative estimates of cancer risks: holding generally true for 35 years," Journal of the National Cancer Institute, vol. 107, no. 4, 2015.

[24] K. J. Mukamal, K. M. Conigrave, M. A. Mittleman et al., "Roles of drinking pattern and type of alcohol consumed in coronary heart disease in men," New England Journal of Medicine, vol. 348, no. 2, pp. 109-118, 2003.

[25] D. Schmähl, R. Preussmann, and M. R. Berger, "Causes of cancer-an alternative view to doll and peto (1981)," Klinische Wochenschrift, vol. 67, no. 23, pp. 1169-1173, 1989.

[26] W. Boerckel, D. Donaldson, and Wilson, Improving the Quality of Life for Lung Cancer Patients, Lung Cancer Advocacy Group Websites, Washington, DC, USA, 2015.

[27] A. Najdi, M. Berraho, K. Bendahhou et al., "Les déterminants du statut "perdu de vue" chez les patients pris en charge pour cancer au Maroc," The Pan African Medical Journal, vol. 18, 2014.

[28] M. Polak, A. Genowska, K. Szafraniec, J. Fryc, J. Jamiołkowski, and A. Pająk, "Area-based socio-economic inequalities in mortality from lung cancer and respiratory diseases," International Journal of Environmental Research and Public Health, vol. 16, no. 10, p. E1791, 2019.

[29] K. El Rhazi, B. Bennani, S. El Fakir et al., "Public awareness of cancer risk factors in the Moroccan population: a populationbased cross-sectional study," BMC Cancer, vol. 14, no. 1, p. 695, 2014. 


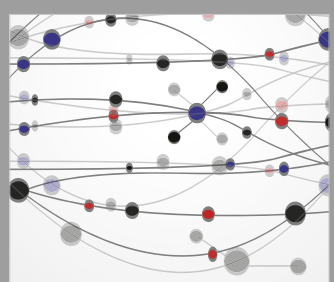

The Scientific World Journal
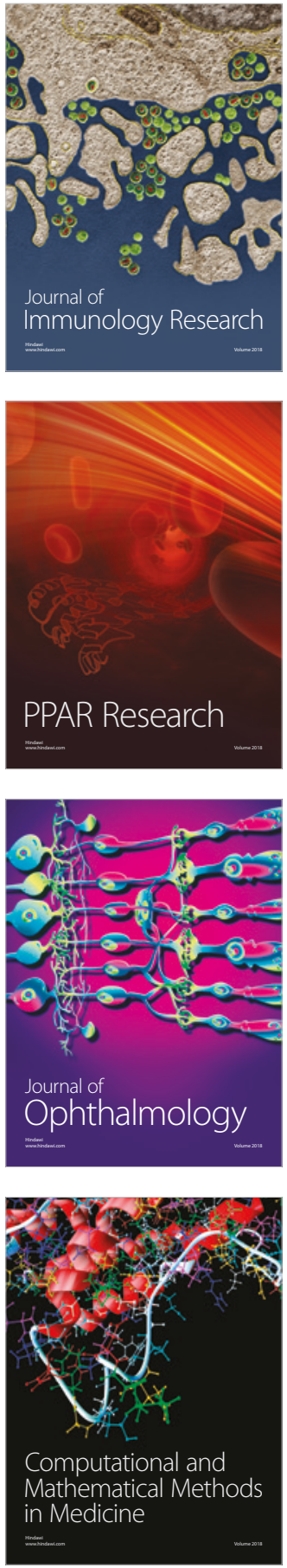

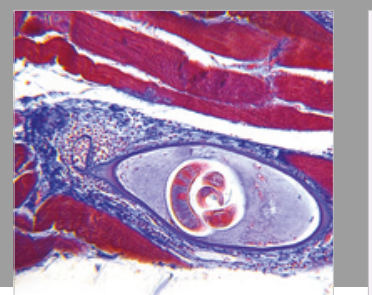

Gastroenterology Research and Practice

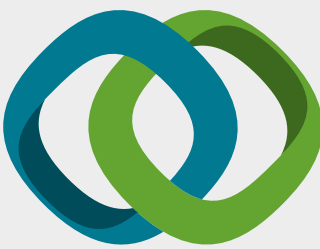

\section{Hindawi}

Submit your manuscripts at

www.hindawi.com
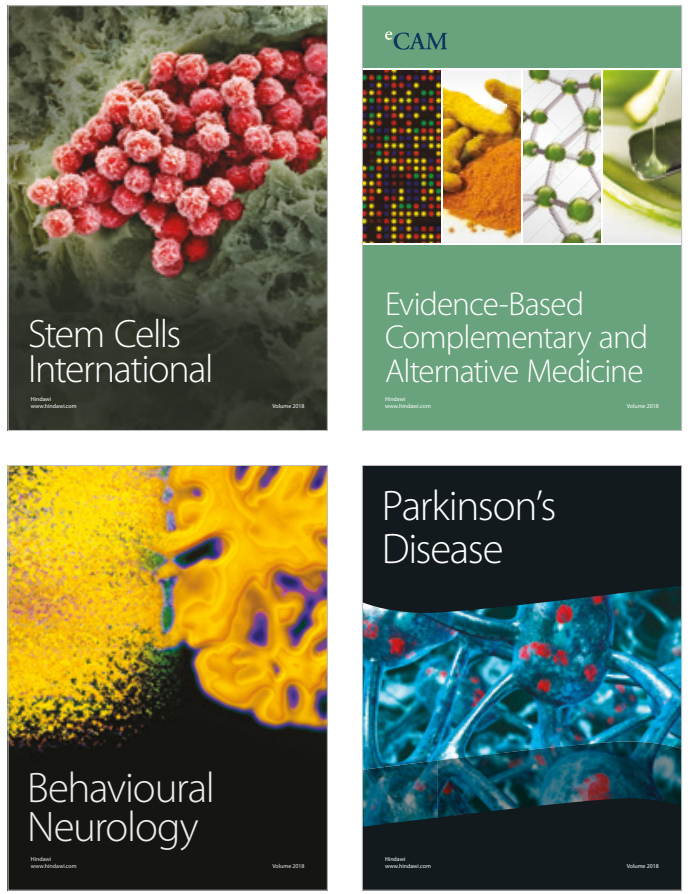

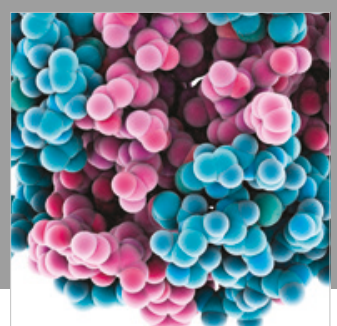

ournal of

Diabetes Research

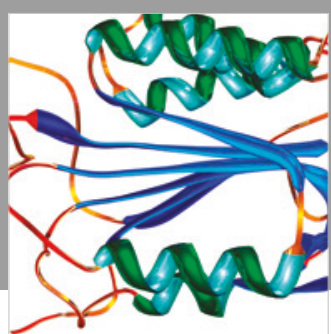

Disease Markers
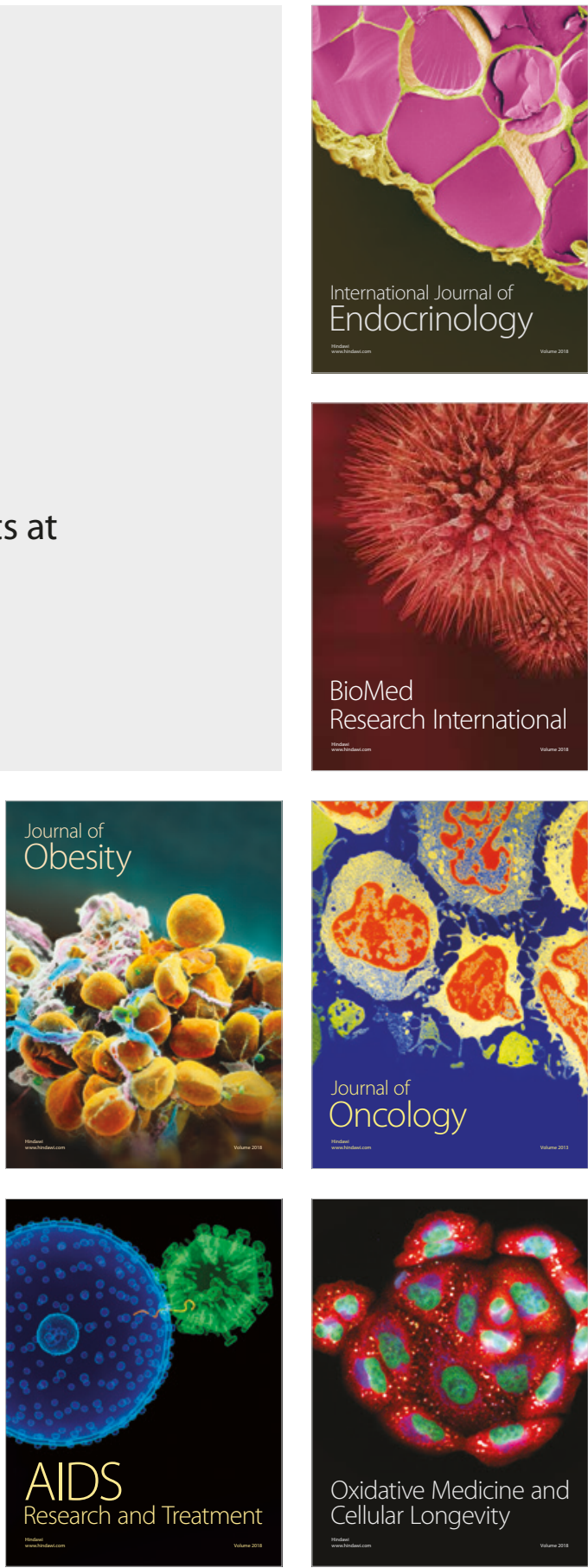